\title{
Sobre a Fusão Nuclear de Deuterões induzida electroquimicamente
}

\section{Introdução}

$\mathrm{Na}$ sequência de importante e sensacional conferência de imprensa, o prestigiado diário inglês «Finantial Times" publicava uma notícia na primeira página, no passado 23 de Março, que rapidamente tirou do anonimato, do público em geral, dois ilustres electroquímicos. Foram eles Martin Fleishmann, checoslovaco naturalizado inglês da Universidade de Southampton, e Stanley Pous, americano da Universidade de Utah. Anunciaram, por estes meios, os resultados das suas experiências sobre a electrólise de uma solução de hidróxido de lítio deuterado em água pesada, sendo utilizados, no cálculo e no ânodo, paládio e platina, respectivamente. Da experiência resultava a produção de energia, sob a forma de calor, em quantidade muito superior àquela que era consumida, além naturalmente da libertação de deutério no cátodo e oxigénio no ânodo [1].

Atribuiram, os cientistas, tal fenómeno a reacçð̃es de fusão nuclear a frio que decorriam nos interstícios da estrutura do paládio a partir dos iões deutério, provenientes da solução, que para aí migravam sob a pressão galvanostática $\left.{ }^{1}\right]$.

A notícia provocou e continua a provocar vasta polémica no mundo da ciência, uma vez que a experiência total ou parcial tem sido tentativamente reproduzida em diferentes locais sem que os resultados pareçam confirmar o optimismo inicial. De qualquer modo, a corrida aos laboratórios, mesmo em Portugal, continua, e químicos, físicos e especialistas de materiais tentam interpretar ou repetir aquilo que foi observado pelos dois referidos cientistas.

$\mathrm{O}$ caso não é para menos e a verdade é que, a confirmarem-se estas experiências, a humanidade passaria a dispor de um combustivel barato, pois com relativa facilidade o deutério poderia ser concentrado a partir da água do mar e, na essência, os seus problemas energéticos estariam resolvidos. Estar-se-ia, porventura, perante o feito científico de maior impacto, depois da $2 .{ }^{\mathrm{a}}$ Guerra Mundial, ultrapassando mesmo as descobertas da penicilina, da descodificação genética com o conhecimento do modelo estrutural do DNA e da sua síntese e do conjunto de investigaçð̄es que têm permitido avanços espectaculares no conhecimento do universo aero-espacial.

\section{Algumas características do trabalho de Fleishmann, Pous e Hawkins}

No aspecto tecnológico a investigação é de simplicidade relativamente grande, embora os mecanismos reaccionais, influenciados entre outros factores pela natureza dos eléctrodos metálicos mergulhados na solução, não estejam, ainda hoje, completamente resolvidos apesar de, desde há cerca de 190 anos, depois de Nicholson e Carlisle, muitos cientistas se terem ocupado com a interpretação da electrólise da água e suas soluçðes [ $\left.{ }^{2}\right]$. O primeiro artigo apresentado, como nota prelimiar, por Fleishmann e Pous conjuntamente com Hawkins no Journal of Electroanalytical Chemistry e intitulado «Electrochemically induced nuclear fusion of deuterium" [ $\left.{ }^{1}\right]$ vem naquela linha, sobretudo da dos mais recentes, em que se estuda a evolução do deutério e do trítio provenientes da electrólise, usando paládio como material catódico.

Esta reação segue, de acordo com os pontos de vista mais gerais, os seguintes passos mecanísticos:

$\mathrm{D}_{2} \mathrm{O}+\mathrm{e}^{-} \longrightarrow \mathrm{D}_{\text {ads }}+\mathrm{OD}^{-}$
$\mathrm{D}_{\text {ads }}+\mathrm{D}_{2} \mathrm{O}+\mathrm{e}^{-} \longrightarrow \mathrm{D}_{2}+\mathrm{OD}^{-}$

A estes dois passos está associada a evolução de deutério, $\mathrm{D}_{2}$, por forma que o potencial químico do ião $\mathrm{D}^{+}$ dissolvido, seja, normalmente, determinado pelas suas velocidades relativas.

A estas reacçð̃es parciais, seguindo a argumentação de Fleishmann e Pous, seguem-se mais duas, uma das quais está directamente relacionada com a forma como o deutério iónico migra com grande mobilidade na fase $\beta$ da estrutura metálica, maior aliás do que na fase $\alpha$, mais simétrica e menos distorcida.

Esquematicamente, tem-se, então:

$\mathrm{D}_{\text {ads }} \longrightarrow \mathrm{D}_{\text {rede }}$

e/ou recombinação de dois átomos de deutério:

$\mathrm{D}_{\text {ads }}+\mathrm{D}_{\text {ads }} \longrightarrow \mathrm{D}_{2}$

O estabelecimento de sobretensð̃es negativas na interface de saída do eléctrodo de paládio para a descarga do hidrogénio na interface de entrada, determinada pelo balanço de todos os passos (i) a (iv), justifica que o potencial químico possa atingir valores bastante elevados. Referem Fleishmann e Pous que, trabalhando com tubos de difusão de paládio, estes potenciais poderão chegar a $0,8 \mathrm{eV}$ e, em alguns casos, até a 2,0 eV.

Estes valores são de tal forma astronómicos que, para tal, seriam, no passo (iv), necessárias compressőes de deutério que, no mínimo, requereriam pressð̃es de $10^{26}$ atmosferas. Pois, apesar desta elevada compressão, não

\footnotetext{
a Centro de Electroquimica e Cinética da Universidade de Lisboa Faculdade de Ciências, Instituto Bento da Rocha Cabral, Calçada Bento Rocha Cabral, 14, 1200 Lisboa.
} 
é formado deutério, $\mathrm{D}_{2}$, e a razão de tal pode residir em factores mecânicos-quânticos associados ao muito baixo carácter $s$ dos electrões em volta dos núcleos e estes encontrarem-se bastante deslocalizados.

Não deixa de ser interessante e importante, nesta investigação, o valor bastante elevado do factor de separação H/D para o hidrogénio e o deutério absorvido, no caso do paládio [ $\left.{ }^{3}\right]$. Este aspecto é tanto mais de acentuar quanto tal factor é, geralmente, obtido com grande rigor experimental e resulta das velocidades relativas da evolução de hidrogénio e deutério, sendo a do último isótopo naturalmente muito menor.

Em face disto e da muita elevada compressão e mobilidade das espécies dissolvidas, concluem os autores que deve haver um número significativo de colisð̃es próximas, o que permite pôr a questão:

Será realizável a fusão nuclear de $\mathrm{D}^{+}$, tal como:

${ }^{2} \mathrm{D}+{ }^{2} \mathrm{D} \longrightarrow{ }^{3} \mathrm{~T}(1,01 \mathrm{M} \mathrm{eV})+{ }^{1} \mathrm{H}(3,02 \mathrm{M} \mathrm{eV})$

ou

${ }^{2} \mathrm{D}+{ }^{2} \mathrm{D} \longrightarrow{ }^{3} \mathrm{He}(0,82 \mathrm{M} \mathrm{eV})+\mathrm{n}(2,45 \mathrm{M} \mathrm{eV})$

sob estas condições?

Neste trabalho, o ião $\mathrm{D}^{+}$foi, como atrás se refere, comprjmido galvanostaticamente em amostras de paládio de diferentes formas e dimensões e os potenciais de eléctrodo foram medidos em relação a um eléctrodo de referência Pd-D carregado para o equilíbrio de fases $\alpha-\beta$. Para determinar a produção de calor realizaram-se medidas calorimétricas a baixas e elevadas densidades de corrente e os resultados expressos em excesso de entalpia mostraram que os cátodos de forma cilindrica envolvidos por hélices de fio de platina eram os mais aproriados, sendo o rendimento fortemente dependente, do diâmetro do cilindro de paládio.

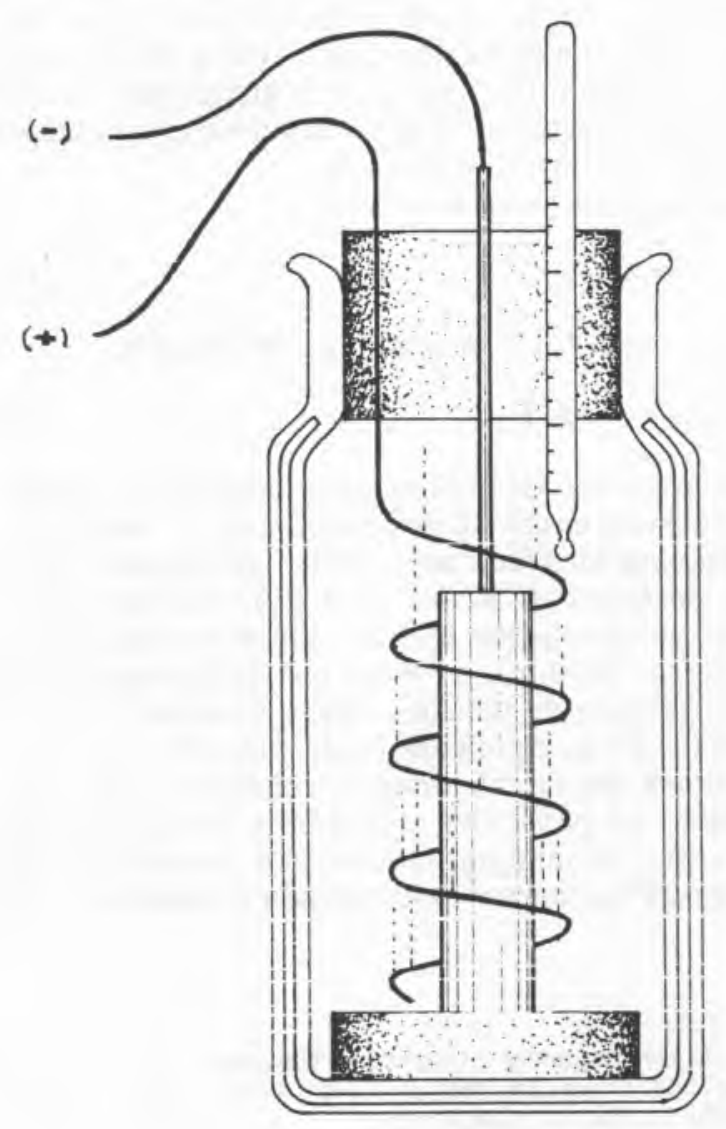

No sentido de estimar a produção neutrónica foi feita espectrometria $\gamma$, tendo em conta, para o fundo, a reacção $(n, \gamma)$ do banho de água.

${ }^{1} \mathrm{H}+\mathrm{n}(2,45 \mathrm{M} \mathrm{eV})={ }^{2} \mathrm{D}+\gamma(2,5 \mathrm{M} \mathrm{eV})$

Afirma-se que os resultados daqui derivados confirmam a existência de neutrões de $2,45 \mathrm{M} \mathrm{eV}$ gerados nos eléctrodos pela reacção (vi).

$\mathrm{O}$ facto experimental mais surpreendente para Fleishmann e Pous foi, acaso, a observação de se gerarem neutrões e tritério a partir de $\mathrm{D}^{+}$comprimido electroliticamente em eléctrodo de paládio e que as reacções (v) e (vi) sejam só uma pequena parte do esquema global das reacçðes, sendo a totalidade da energia libertada devida a um processo ou processos nucleares desconhecidos, presumivelmente devidos a deuterð̌es.

De notar, a este propósito, que, recentemente, J. Salgado e P. Matos do Laboratório Nacional de Engenharia e Tecnologia Industrial, dispondo de todo o material necessário, nomeadamente, detectores de raios $\gamma$, de neutrões e outro de trítio (único no pais), montaram a experiência e, até agora, não observaram a libertação de qualquer das três espécies, raios $\gamma$, neutrões e/ou trítio, o que seria uma indicação da eventual ocorrência de fusão [ [4].

Este é um exemplo de uma prova negativa de uma experiência que a ter-se realizado positivamente constituiria uma técnica prática para se obter uma fonte de energia, virtualmente, ilimitada. Além disso, o processo não geraria poluentes - nem mesmo dióxido de carbono que tanto se teme pelo aquecimento do globo, resultante de um efeito de estufa - na medida em que os perigos de contaminação numa fusão são nulos, quando comparados com as cisões nucleares, que se observam nos geradores termo-nucleares.

E uma ideia que pelo menos fica; é algo que provocou, como disse, grande frenesi entre os cientistas, revisão de conceitos e aperfeiçoamento de experiências.

\section{Alguns aspectos \\ sobre a polémica relativa à experiência de Fleishmann e Pous}

A polémica deu-se; a polémica continua.

Muitos cientistas zombaram dos químicos que tinham causado que ið̌es deutério fundissem para formarem hélio, libertando grandes quantidades de calor.

No entanto, quatro dias depois da apresentação do trabalho de Fleishnamm e Pous, Steven Jones, físico nuclear da Universidade de Bringham Young, que há cerca de dois anos vinha investigando sobre o efeito catalítico muónico, sobre a fusão nuclear, apresenta um trabalho na Nature $\left[^{5}\right]$, com largo número de colaboradores, onde se trata da observação de fusão nuclear fria em matéria condensada, e onde se procura mostrar que quando uma corrente passa através de eléctrodos de paládio ou de titânio imersos num electrólito de água deuterada e diferentes sais, é detectado um pequeno, mas significativo, fluxo de neutrões. A fusão de deuterões no interior da rede metálica pode ser a explicação. Observa e mede este grupo a produção de neutrōes; no entanto, não detectou, com o seu sistema, a produção de calor.

De notar que nenhum dos grandes laboratórios nacionais americanos obtiveram resultados positivos dentro dos parâmetros definidos por Fleishmann e Pous, e cientistas do Japão e da Suíça anunciaram que os testes 
por eles realizados, os levara a concluir que se tinha chegado a uma conclusão apressada baseada numa investigação apressada [ $\left.{ }^{6}\right]$.

Um dos mais completos conjuntos de experiências resultou de uma colaboração entre laboratórios Nacionais de Brookhaven e a Universidade de Yale e os resultados apresentados no Encontro da Primavera da Sociedade Americana de Física não mostram evidência para o que foi afirmado por Pous e Fleishmann.

O físico de Brookhaven, Kelvin Lynn, especula que, possivelmente, o calor produzido pode ser 0 resultado de alguma mais convencional, embora inesperada, reacção química. Diz «É bastante interessante saber como a natureza pode ter conspirado para fazê-los acreditar que eles tinham fusão".

A conclusões análogas chega o laboratório britânico de Harwell [ ${ }^{6}$ ].

John Maddox, editor da Nature, que publicou os resultados de Jones e não os de Fleshmann e Pous, escreve: «é literalmente desapoiado pela experiência, pode ser um artefacto (um resultado espúrio não relacionado com o fenómeno sob investigação) e, dada a sua improbabilidade, é mais natural sê-lo». Maddox notava, ain$\mathrm{da}$, que o "team» anunciou os seus resultados mesmo antes de realizar as experiências mais básicas para confirmarem as descobertas, ... um ofuscante lapso a partir da prática aceite $\left[{ }^{7}\right]$.

Por outro lado, Robert Huggins, respeitado cientista de ciências de materiais, de Stanford, sustenta que também ele obteve excesso de calor numa série de experiências similares. Refere que «os efeitos observados por nós são comparáveis aos relatados anteriormente por Fleishmann e Pous e emprestam forte suporte à validade dos seus resultados $\left[{ }^{6}\right]$.

Dois ou três meses depois deste abalo científico, a experiência foi sendo tentada, também, noutras Universidades americanas e em diferentes países, na União Soviética, na Inglaterra, na Itália, na Hungria, na Checoslováquia, no Brasil, na Índia e em Portugal. Muitos observaram a libertação de neutrões, mas a produção de energia nunca foi significativa [ $\left.{ }^{4}\right]$.Exceptua-se, porventura, um grupo de investigadores da Universidade do Texas que na Conferência Internacional sobre Fusão Nuclear, confirmou os resultados obtidos por Fleishmann e Pous. John Appleley, daquela Universidade, en- tende que o trítio e os neutrõs libertados só podem resultar de uma fusão nuclear [ ['].

Sobre o assunto, Valera, físico do estado sólido da Faculdade de Ciências de Lisboa, diz que uma hipótese possível é a rede cristalina de paládio estar destruída em alguns pontos, o que pode funcionar como agente de encontro dos átomos de deutério, promovendo a sua fusão com consequente libertação de neutrões e de calor. Nenhuma das críticas significa que Fleishmann e Pous estão necessariamente errados. Mas a carga da prova permanece com eles, tanto mais que os cientistas não foram pródigos na descrição das suas experiências e a sua explicação de que tinham produzido uma nova forma de fusão é, por isso, pouco convincente, além de não interpretarem o excesso de energia na sua experiência. Sobre isto, por exemplo, o prémio nobel da química e da paz, Linus Pauling pensa que a rede de paládio quando se encontra absorvendo elevadas concentrações de deutério, pode tornar-se instável e deteriorada, libertando por isso, calor $\left[{ }^{8}\right]$.

De qualquer forma, de toda esta discussão e polémica que aqui só se refere em muito pequena parte, tirar-se-ão muitas conclusð̃es, tanto positivas, como negativas. Talvez o aproveitamento de energia a partir da fusão fria de deutério, ainda esteja longe. A verdade é que mesmo estes avanços e recuos observados como consequência do trabalho de Fleishmann, Pous e Hawkins não foram, certamente, neutros para o progresso da ciência e poderão contribuir para o esclarecimento de certas questōes, por exemplo, sobre o que se passa com os compostos intersticiais de deutério e paládio ao nível da rede cristalina.

\section{Referências}

[1] Fleishmann, M., Pous, S. e Hawkins, M., J. Electroanal. Chem. 261, (1989), 301.

[2] Partington, J.R., "A History of Chemistry» Ed. The MacMillan Press Ltd, Londres (1972) p. 19.

[3] Bockris, J.O.M. e Reddy, A.K.N., "Modern Electrochemistry" Vol. 2, A Plenum/Rosetla Edn. New York, 1977.

[4] Naves, F. Ciência (1989), 48.

[5] Jones, S.E., Palmer, E.P., Czirr, J.B., Decker, D.L., Jensen, G.L., Thorne, J.M., Taylor, S.F. e Rafekski, J., Nature, 338 (1989), 737.

[6] Lemonick, M.D., Science, Time (1989), 44.

[7] Maddox, J., Nature, 337 (1989), 600.

[8] Pauling, L., Nature, 339 (1989), 105.
FÓSFORO, de phosphoros, ou contentor de luz; descoberto em 1669; ocorre em três formas: branco, vermelho, e, raramente, negro. O fósforo branco é instável, amarelece e depois avermelha à luz e brilha no escuro (fosforescência). Os fosfatos são ingredientes dos detergentes.

ENXOFRE, de sulphur, nome bíblico; conhecido desde os tempos antigos. É usado em todos os ramos da indústria moderna, no fabrico de fósforos, insecticidas e tiras de borracha, entre outros. Cerca de $100 \mathrm{~kg}$ de ácido sulfúrico per capita, por ano, são produzidos nos Estados Unidos. 

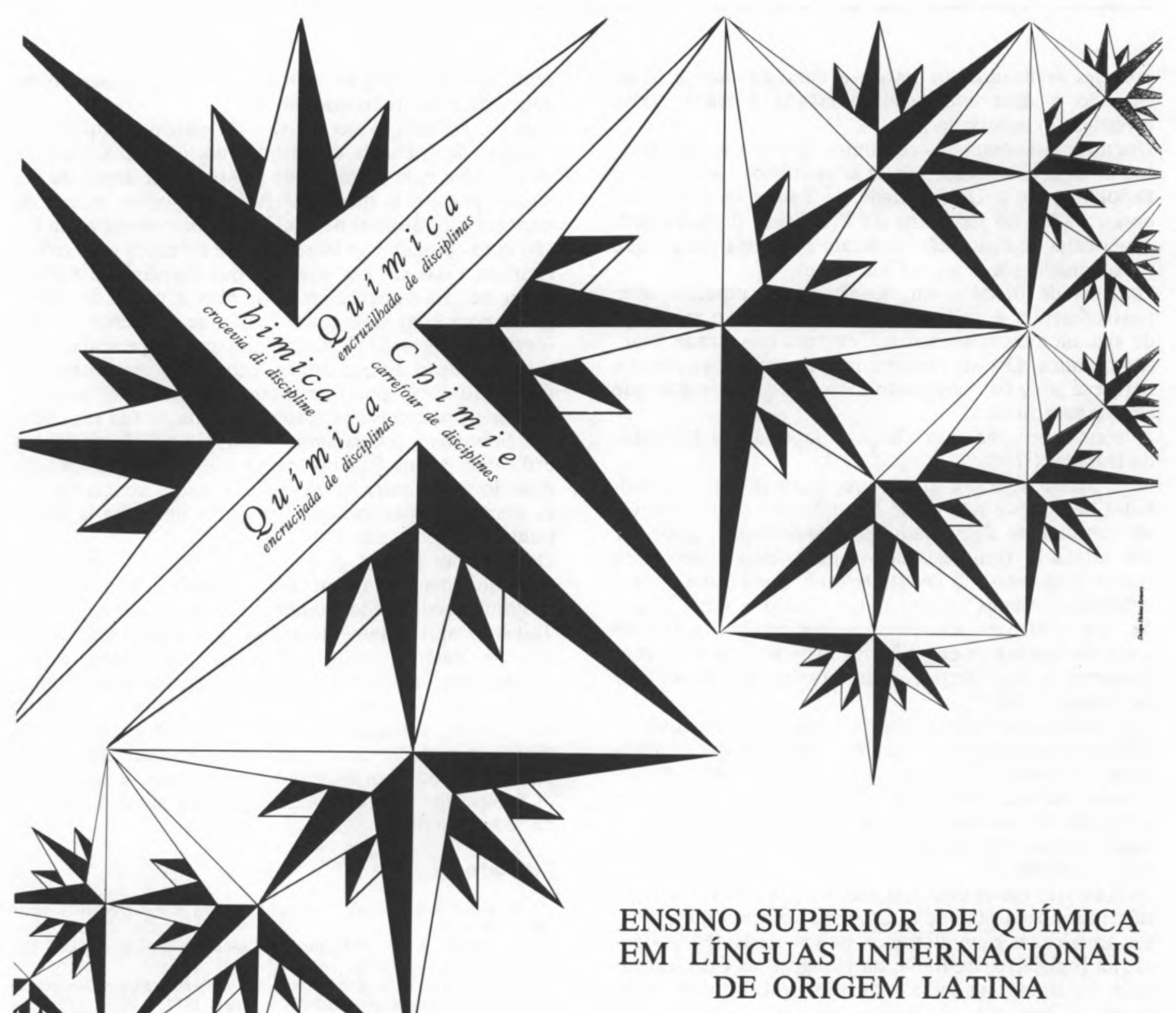

LISBOA 8-10 DE NOVEMBRO 1989

A Sociedade Portuguesa de Química (SPQ), juntamente com a Faculdade de Ciências de Lisboa e a União Latina está a organizar um Colóquio Internacional sobre Ensino Superior de Química em Línguas Internacionais de Origem Latina.

Colaboram nesta realização Service Enseignements Supérieurs - Didactique de la Chimie, SESDiC; Reseau des Enseignants de Chimie en Langue Française, RECLAF; Societé Française de Chimie, SFC; Societé Royale de Chimie (Belgique), SRC; Real Sociedad Española de Quimica, RSEQ; Université Libre de Bruxelles; Université de Mons; Université de Poitiers; Université de Rennes; Universidad de Valladolid. O Colóquio realizar-se-á de 8 a 10 de Novembro de 1989 na Fundação Gulbenkian, em Lisboa.

O $1 .^{\circ}$ Colóquio Internacional tem como objectivo final o estabelecimento de bases concretas para o desenvolvimento de projectos cooperativos para o Ensino de Química em Línguas Latinas.

Dirige-se prioritariamente a professores do ensino terciário e dos anos terminais do ensino secundário, a formadores de professores e a orientadores de estágio. 